\title{
Mechanical Design and Testing of the MOMA Flight Model Laser Head for the ExoMars 2020 Mission
}

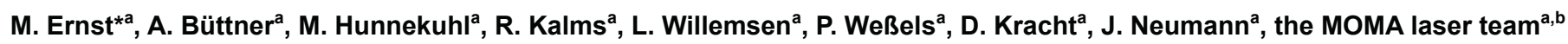

a Laser Zentrum Hannover e.V., Hollerithallee 8, 30419 Hannover, Germany

${ }^{b}$ Max Planck Institute for Solar System Research, Justus-von-Liebig-Weg 3, 37077 Göttingen, Germany

* m.ernst@Izh.de; phone 00495112788 258; fax 00495112788 100; www.Izh.de

The flight model of a hermetically sealed laser head (LH) emitting laser pulses at a wavelength of $266 \mathrm{~nm}$ has been developed and tested for the Mars Organic Molecule Analyzer (MOMA) instrument of the ESA Roscosmos ExoMars 2020 mission. MOMA comprises a gas chromatograph (GC) and a laser desorption mass spectrometer (LDMS). Its primary function is to find present or past life by searching for organic molecules in subsurface material samples.

The $L \mathrm{H}$ is used as an excitation source for the mass and volume requirements and is realized as hermetically sealed system.
It consists of a laser diode pumped, $\mathrm{Nd}$ :Cr:YAG based aser oscillator, a frequency conversion stage, and a compact monitoring stage for internal laser pulse detection.

The system has undergone extensive functional and environmental testing including vibration, shock and thermal vacuum chamber tests. After completion of the functional and environmental test campaign, the $\mathrm{LH}$ has been integrated to the MOMA mass spectrometer. Furthermore, the LH was successfully IDMS level.
D UV Laser @ 266 nm for Martian subsurface analysis

D First LDMS to search for extraterrestrial life

> Compact, lightweight and hermetically sealed design

D LH flight model environmentally tested and integrated

TRL 8 for LH and MS Instrument
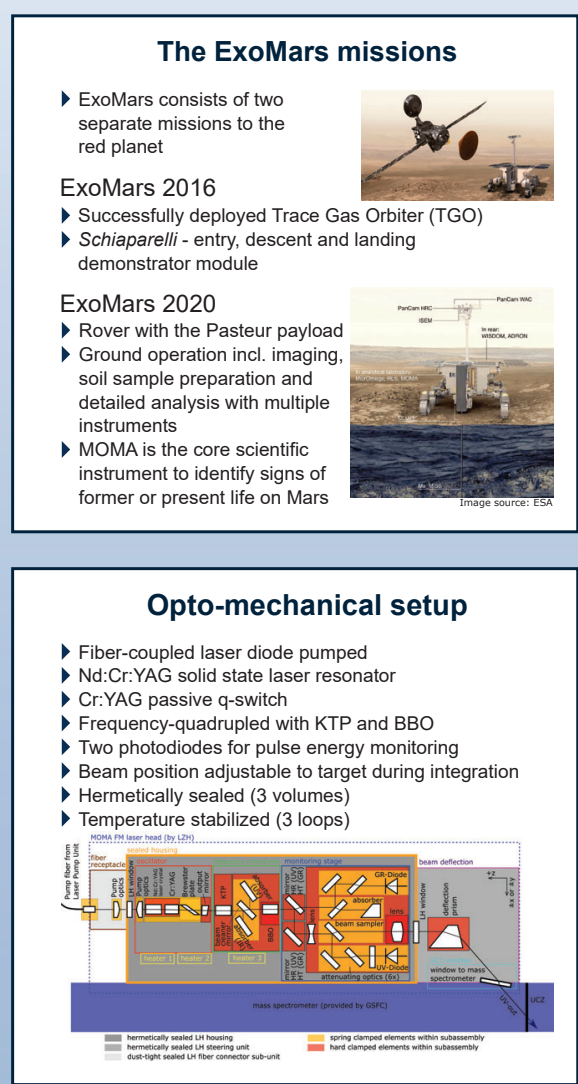

Laser head environmental tests II

- Thermal vacuum test with $L H$ and LPU

- Thermal cycles from $-55^{\circ} \mathrm{C}$ to $+60^{\circ} \mathrm{C}$ (non-op) and $-45^{\circ} \mathrm{C}$ to $+25^{\circ} \mathrm{C}$ (op)

- Performance tests at Mars atmosphere $\left(\sim 10 \mathrm{mbar} \mathrm{CO}_{2}\right)$

- Chamber external imaging of fluorescence target for

pointing measurement

External energy measurement for calibration of internal photodiodes

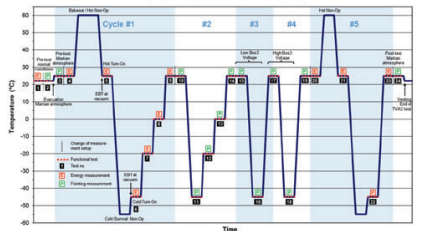

MOMA within the ExoMars rover

- Combined gas chromatograph (GC) and mass spectrometer (MS) with additional laser desorption mode (LDMS)

- GCMS looks for volatile compounds and LDMS is

capable to detect molecules up to $1000 \mathrm{u}$ in Martian soil samples

LDMS is novel for extraterrestrial search for life

Integrated into analytical lab drawer (ALD)

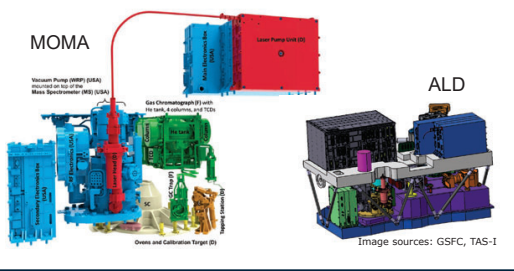

Structural and thermal analysis

Structural mechanical and modal analysis

(Quasi-) static loads (for pressure and acceleration)

- Random vibration or shock loads

Steady-state thermal simulation

- Operational heat distribution

Heating power consumptio

Thermo-mechanical simulation

- Transient thermal heat up cases
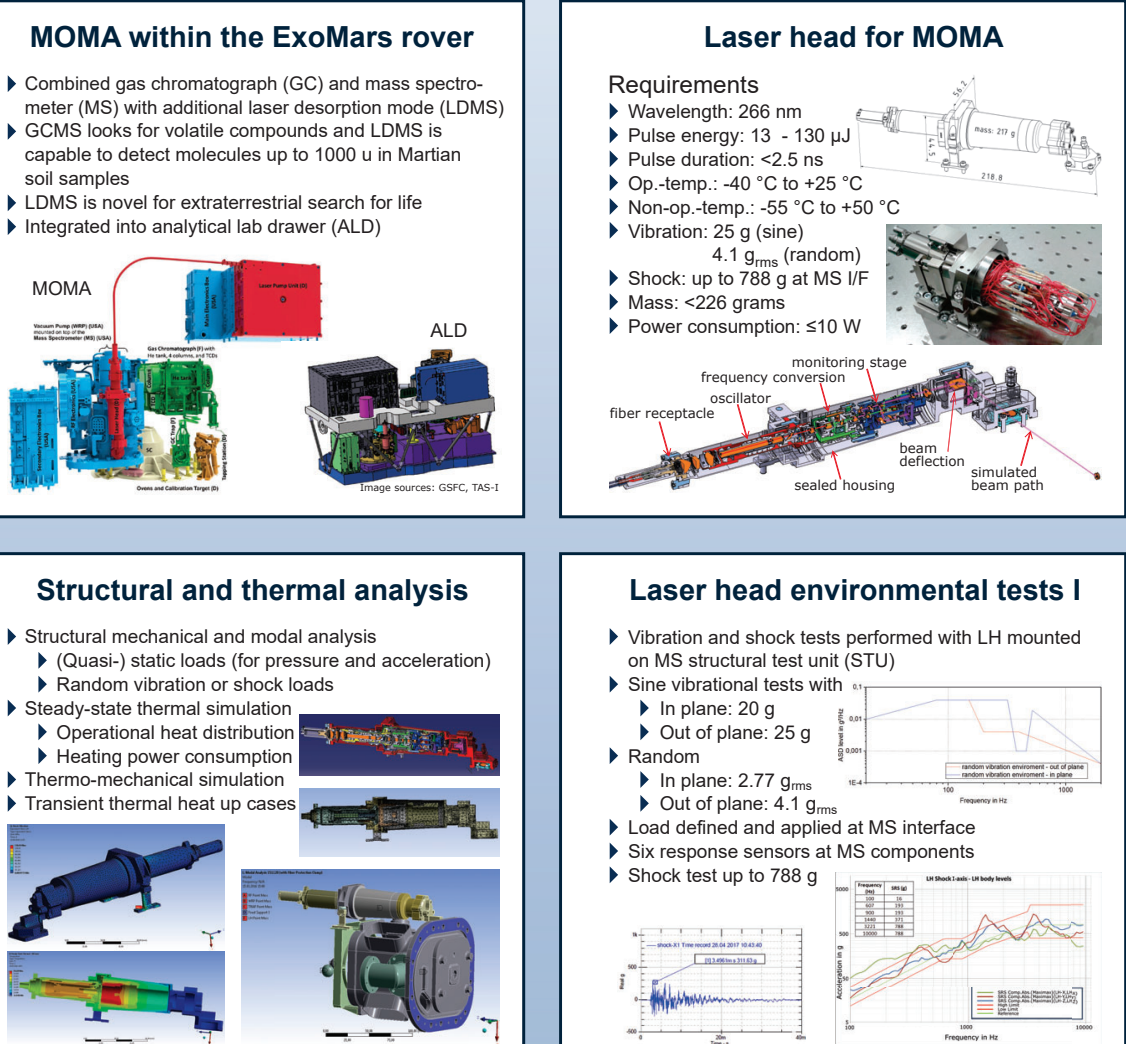

Laser head environmental tests I

Vibration and shock tests performed with LH mounted

on MS structural test unit (STU)

Sine vibrational tests with

In plane: $20 \mathrm{~g}$

- Out of plane: 25

- Random

In plane: $2.77 \mathrm{~g}$

Out of plane: $4.1 \mathrm{~g}$

- Load defined and applied at MS interface

- Six response sensors at MS components

Shock test up to $788 \mathrm{~g}$
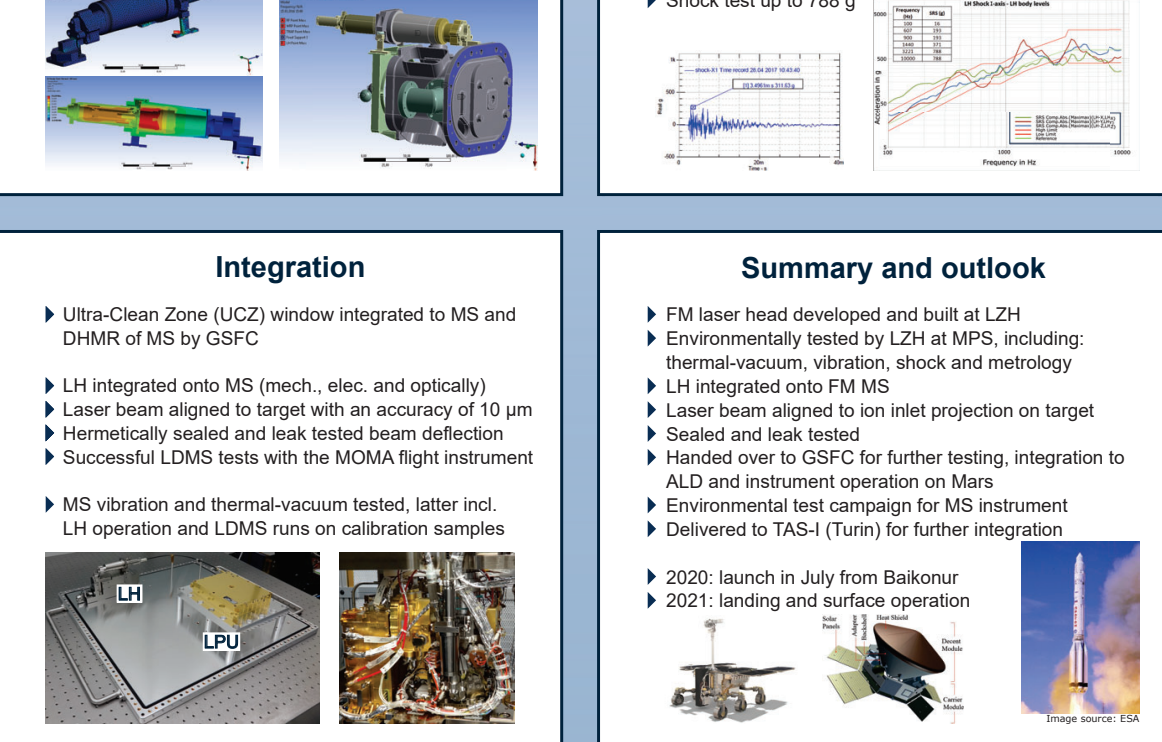

Summary and outlook

- FM laser head developed and built at L Z H

- Environmentally tested by LZH at MPS, including:

thermal-vacuum, vibration, shock and metrology

- LH integrated onto FM MS

- Laser beam aligned to ion inlet projection on target

- Sealed and leak tested

- Handed over to GSFC for further testing, integration to

ALD and instrument operation on Mars

- Environmental test campaign for MS instrument

- Delivered to TAS-I (Turin) for further integration

2020: launch in July from Baikonur

- 2021: landing and surface operation

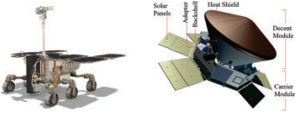

